\title{
Advances in Ultra High Temperature Ceramics For Hot Structures
}

\author{
By Luigi Scatteia ${ }^{1)}$, Federico MonteVerde2) , Davide AlfanO1), and Stefania CAnTONI ${ }^{1}$ ) \\ 1) CIRA - Centro Italiano Ricerche Aerospaziali, Capua (CE), Italy \\ 2) CNR - ISTEC - Istituto per la Scienza e Tecnologia dei Ceramici, Faenza, Italy
}

(Received April 25th, 2008)

\begin{abstract}
The objective of this paper is to describe the current state of the art of the research on Ultra High Temperature Ceramic materials with particular reference to their space applications, and also to report on the activities performed on UHTC in the past decade by the Italian Aerospace Research Centre in the specific technological field of structural thermal protection systems. Within several internal research project, various UHTC composition, mainly based upon Zirconium Diboride and Hafnium Diboride with added secondary phases and sintering aid were examined characterized in their mechanical properties and oxidation resistance. Two main composition were selected as the most promising for hot structure manufacturing: these materials were extensively characterized in order to obtain a comprehensive database of properties to feed the thermomechanical design of prototype hot structures. Technological demonstrators were manufactured by hot pressing followed by further fine machining with Electrical Discharge methods, and then tested at high temperature for long times in a plasma torch facility. The main outstanding results obtained are discussed in this paper. Future outlooks related to the UHTC technology and its further development are also provided.
\end{abstract}

Key Words: UHTC, Hot Structures, Atmospheric Re-entry

\section{Introduction}

Zirconium diboride $\left(\mathrm{ZrB}_{2}\right)$ and hafnium diboride $\left(\mathrm{HfB}_{2}\right)$ belong to a group of ceramic materials commonly referred to as Ultra High Temperature Ceramics (UHTC), for their chemical stability, high melting temperatures, and high thermal conductivity. UHTCs represent a class of promising materials for use in extreme chemical and thermal environmental associated with hypersonic flight and for applications such as sharp leading edges hot structures on future generation of slender-shaped re-entry vehicles, because of their high melting point and relatively good oxidation resistance in re-entry conditions $^{1)-8)}$.

Ultra High Temperature Ceramics have been studied as candidate materials for the manufacturing of structural thermal protection systems since various decades.

As illustrate in ref. 1 and 4, the research on this class of materials first started in the 1960 and 70's in the frame of Air Force sponsored contracts. The early works were devoted to the production of dense materials by mean of pressure assisted sintering, and to investigate the influence of a variety of additives, ${ }^{1), 8)-11)}$ including carbon and silicon carbide $(\mathrm{SiC})^{1), 7), 8), 12)-14)}$, in order to improve the oxidation resistance of $\mathrm{Hf}$ and $\mathrm{Zr}$ diborides. These works showed that the addition of $\mathrm{SiC}$ as secondary reinforcing phase provides significant enhancements to the oxidation resistance of UHTCs as well as to improve the processing by lowering sintering temperatures ${ }^{15)}$. Many other studies were conducted on different compositions and their effects on the oxidation resistance performances of UHTCs, mainly in static air and ambient pressure, while few studies have evaluated the oxidation behavior under simulated re-entry conditions ${ }^{6)-8), 16)-23)}$.

NASA started in 1990 a research program on UHTCs, and ended up demonstrating in-flight in $1997^{24)}$ and 2000 the use of $\mathrm{ZrB}_{2}$ and $\mathrm{HfB}_{2}$ sharp leading edge in the Sharp Hypersonic Aero-thermodynamic Research Probe Ballistic experiments (SHARP-B1 and B2). Further research activities have since then been conducted in the U.S. by NASA Ames, SRI, University of Missouri Rolla, Naval Surface Warfare Center, focused on the characterization of mechanical and chemical properties ${ }^{1), 4), 8), 25)-26)}$ as well as on the evaluation of alternative fabrication processes like co-extrusion ${ }^{27)}$ for $\mathrm{ZrB}_{2}$ - and $\mathrm{HfB}_{2}-\mathrm{SiC}$.

During the $90 \mathrm{~s}$, a wide range research activity on UHTC materials was conducted in Italy, mainly by the Italian National Research Council Institute of Ceramic Materials (CNR-ISTEC). The CNR-ISTEC investigated new processing routes based on pressure assisted sintering, on the adoption of sintering aids and secondary reinforcing phases in order to obtain dense bodies characterized by superior oxidation resistance and mechanical properties ${ }^{2) 28)-30)}$.

In 2000, the Italian Aerospace Research Centre (CIRA), launched the Sharp Hot Structure (SHS) technological project, in the frame of the Unmanned Space Vehicle (USV) National Program ${ }^{31)}$. The project was intended to gather the national expertise owned by universities, research centers and industries in a structured program aimed at developing the know-how needed for the manufacturing of advanced, high performance hot structures based on UHTC.

Within this paper, the main outstanding results obtained 
within the SHS technological project are presented. Future outlooks related to the possible improvements of the UHTC technology are also provided.

\section{Materials}

During the SHS project, several UHTC compositions, mainly based upon $\mathrm{ZrB}_{2}$, have been examined. A trade-off among those composition was conducted on the basis of a preliminary characterization of the microstructure obtained (evaluated by Scanning Electron Microscopy coupled with Energy Dispersive Analysis - SEM EDS) with hot pressing, and of the oxidation resistance of the final samples (high temperature exposition in air with SEM examination and pre- and post-test gravimetric analysis). At the end of this trade off, two compositions (vol\%) were selected as the most promising ones ${ }^{32)}$ :

Material A: $\quad \mathrm{ZrB}_{2}+15 \mathrm{SiC}$

Material B: $\quad \mathrm{ZrB}_{2}+15 \mathrm{SiC}+x \mathrm{HfB}_{2}$

The amount of $\mathrm{HfB}_{2}$ (i.e $x$ ) ranges from $5 \%$ to 15 vol\%. An amount of $\mathrm{MoSi}_{2}$ less than $5 \%$ is also included in both the initial powder mixtures as a sintering aid.

The two above composition were then extensively characterized in their thermo-mechanical and surface properties. Samples were produced by hot-pressing in vacuum using an induction-heated graphite $\mathrm{die}^{32)}$.

The two materials were subjected to the following characterizations:

- Microstructure: SEM-EDS, X-Ray Diffraction;

- Mechanical properties;

- Oxidation resistance at ultra-high temperature (above $1800^{\circ} \mathrm{C}$ ) under plasma torch exposure;

- Surface properties (emissivity and catalycity).

The main results obtained are described in the following paragraphs.

\section{Characterization Results}

\subsection{Microstructure}

The two sintered UHTC are characterized by uniform, micro-grain sized microstructure that highlights the effectiveness of the hot pressing process. In particular, the examination by SEM of the polished surfaces (Fig. 1) shows in composite A that the SiC particulates are located intergranularly within the $\mathrm{ZrB}_{2}$ matrix, or in agglomerates (5 $\mu \mathrm{m}$ maximum size), while in composite $\mathrm{B}$, the SEM analyses provided evidence of the formation of $(\mathrm{Zr}, \mathrm{Hf}) \mathrm{B}_{2}$ solid solutions: a core-shell configuration of the diboride matrix is evident with the core consisting of $\mathrm{ZrB}_{2}$, and the shell of $(\mathrm{Zr}, \mathrm{Hf}) \mathrm{B}_{2}$ solid solution.
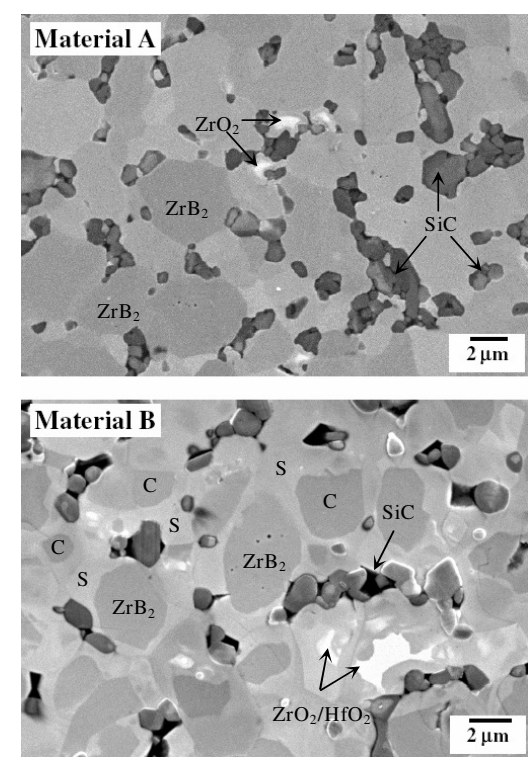

Fig. 1. SEM Images of polished cross-section of UHTC A and B: Shell (S), and core (C)

\subsection{Mechanical properties}

Table 1 and Table 2 the mean grain size (mgs), Vickers micro-hardness HV1.0, Young's modulus E, Poisson ratio $v$, fracture toughness $\mathrm{K}_{\mathrm{Ic}}$, flexural strength $\sigma$, and retained strength after aging $\sigma_{\text {RET }}$ are showed.

Table 1. Mean grain size, micro-hardness, Young's modulus and Poisson ratio of UHTC A and B

\begin{tabular}{|c|c|c|c|c|}
\hline Sample & $\begin{array}{c}m g s \\
(\mu m)\end{array}$ & $\begin{array}{c}\text { HV1.0 } \\
(\mathrm{GPa})\end{array}$ & $\begin{array}{c}\mathrm{E} \\
(\mathrm{GPa})\end{array}$ & $v$ \\
\hline A & 2 & $17.7 \pm 0.4$ & $480 \pm 4$ & 0.13 \\
\hline B & 5 & $18.2 \pm 0.5$ & $506 \pm 4$ & 0.128 \\
\hline
\end{tabular}

Table 2. Fracture toughness, flexural strength and retained strength after aging of UHTC A and B

\begin{tabular}{|c|c|c|c|c|c|}
\hline \multirow{2}{*}{ Sample } & \multicolumn{2}{|c|}{$\begin{array}{c}\mathrm{K}_{\mathrm{Ic}} \\
\left(\mathrm{MPa} \cdot \mathrm{m}^{1 / 2}\right)\end{array}$} & \multicolumn{2}{c|}{$\begin{array}{c}\sigma \\
(\mathrm{MPa})\end{array}$} & $\begin{array}{c}* \sigma_{\mathrm{RET}} \\
(\mathrm{MPa})\end{array}$ \\
\hline & $\mathrm{RT}$ & $1500^{\circ} \mathrm{C}$ & $\mathrm{RT}$ & $1500^{\circ} \mathrm{C}$ & \\
\hline A & $4.07 \pm 0.03$ & $2.53 \pm 0.23$ & $887 \pm 125$ & $255 \pm 25$ & $564 \pm 67$ \\
\hline $\mathrm{B}$ & $4.08 \pm 0.75$ & $3.43 \pm 0.02$ & $763 \pm 73$ & $240 \pm 20$ & $631 \pm 69$ \\
\hline
\end{tabular}

As can be seen from the tables, both materials are characterized by high Young's modulus, micro-hardness that is line with which reported in literature for similar materials ${ }^{4), 6)-8), 12)}$, and flexural strength at room temperature that is very high in comparison to similar ceramics based upon ultra-refractory compounds. The strength at $1500^{\circ} \mathrm{C}$ in air is coherently lower compared to the room-temperature values. Concerning the reduced strength $\sigma_{\text {RET }}$ after aging, i.e cycled treatments at $1600^{\circ} \mathrm{C}$ in air, composite $\mathrm{B}$ retained its initial strength better than composite $\mathrm{A}$, thanks to the higher refractoriness provided by the added $\mathrm{HfB}_{2}$. 


\subsection{Laboratory oxidation tests}

Fig. 2 shows cross section SEM images of materials A and $\mathrm{B}$ after thermal treatment at $1600^{\circ} \mathrm{C}$ in air: the typical oxidation pattern of UHTC materials is evident. A silica-based layer covers the external faces of the oxidized samples. An $\mathrm{MO}_{2}$-based scale underlying the outermost glass coating extends for tenths of microns up to the $\mathrm{SiC}$ depleted zone $\mathrm{z}^{1,7), 17), 19), 20), 30)}$. For temperatures $\geq 1600^{\circ} \mathrm{C}$ in an oxygen-rich environment, the borosilicate layer formed by oxidation can be partially lost by rather quickly evaporation or active oxidation.
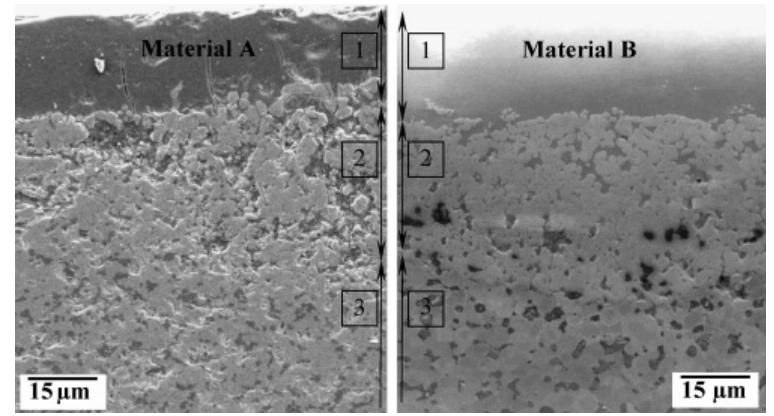

Fig. 2. Polished cross-section of materials A and B after aging (SEM micrographs): external silica glass (1), oxide sub-scale (2), and un-changed volume (3)

\subsection{Emissivity and catalycity}

Considering the impact of emissivity and surface catalycity on the overall heat flow and surface temperatures on a hot structure during the re-entry phase of a space vehicle, it is clear that these two parameters are pivotal to the application of UHTC compounds as TPS materials.. Since these parameters are highly dependent on surface changes during high temperature exposure, and given the complexity and the relative unpredictability of UHTC surface modifications under different operating conditions, the availability of reliable experimental data obtained in relevant testing conditions is almost necessary.

The total hemispherical emissivity and the atomic oxygen recombination coefficient were measured using the MEDIASE and MESOX facilities located at PROMES-CNRS, France ${ }^{33)}$. Both the UHTC composition $\mathrm{A}$ and $\mathrm{B}$, were tested, in samples machined by diamond loaded tools (DLT) or by electrical discharge machining (EDM) in order to evaluate the effect of the surface finish on those properties ${ }^{33), 34)}$.

Figure 3 reports the evolution of the total hemispherical emissivity versus temperature for the four selected materials: A-EDM (dotted line), A-DLT (full line), B-EDM (bold dotted line) and B-DLT (bold dotted line with space).

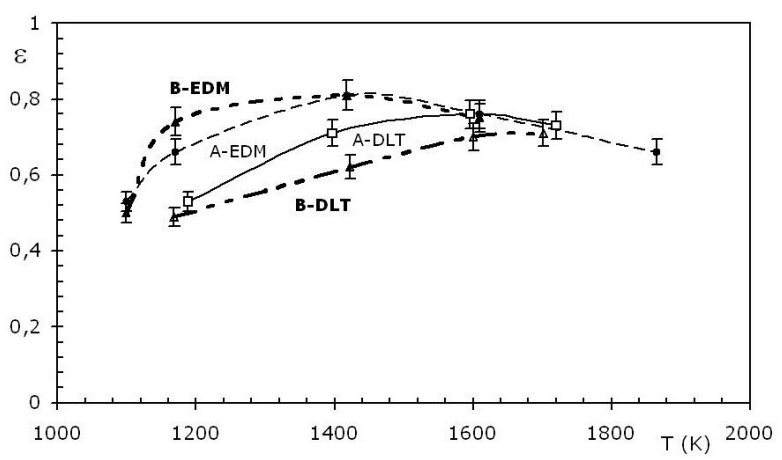

Fig. 3. Total hemispherical emissivity for UHTC A and B machined by EDM and DLT

As can be seen from the graph, all samples exhibit a fairly high emissivity (about 0.7 ) at high T. The surface machining affects the emissivity only at lower temperatures in both compositions with the effect becoming negligible at temperatures above about $1200^{\circ} \mathrm{C}$.

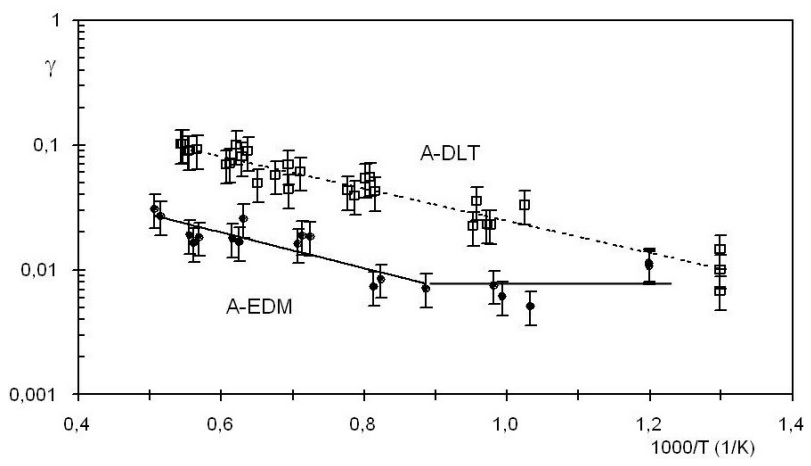

Fig. 4. Atomic oxygen recombination coefficient gamma for material A machined by EDM and DLT

Figure 4 shows the atomic oxygen recombination coefficient gamma for material A machined by EDM and DLT: as can be seen from the graph, on the overall a low catalytic activity can be assumed for this class of UHTC materials, with a maximum value of about 0.1 at $\mathrm{T}$ approaching $1800^{\circ} \mathrm{C}$. It is also evident the effect of the surface finish on the catalytic behavior of this material: the EDM machined sample shows a change in the slope of the gamma curve, presumably connected to a change in the recombination mechanism, while the DLT sample has an higher catalytic activity but follows a typical Arrhenius-like trend. This is probably due to the occurrence of surface oxidation during the EDM machining that slightly changes the surface composition in material A. Conversely, only small variations were found in the recombination coefficients of $\mathrm{ZrB}_{2}-\mathrm{HfB}_{2}$-based samples for the different machining processes.

\subsection{Machinability by Electrical Discharge Machining}

The machinability by EDM of dense UHTC sintered pieces was also studied. An analysis of the surface of 
EDM machined samples has shown that the EDM induce a damage: the surface modifications seem more pronounced in material $B$ due to its higher refractoriness. The SEM-EDS analyses upon the electrical discharged surfaces confirmed the formation of a partially oxidized thin layer, which in turn includes contaminants from the electrically active tools used for $\mathrm{EDM}^{34)}$.

Flexure strength measured upon samples machined with EDM showed a decreased mean value of about $26.4 \%$, compared to that obtained from specimens machined with DLTs, the major reason for this being the micro-cracked surface layer induced by the action of the electrical discharges $^{32)}$.

In spite of those minor hindrances, whose effects can be taken into account and controlled in the design of a thermal structure, the employment of the EDM technique has proven to be effective for shaping a sintered ceramic piece into a more complex medium-scaled component.

\subsection{Plasma torch test on a small UHTC nose cone}

A small UHTC nose-cone made of material A $(5 \mathrm{~cm}$ base diameter, $8 \mathrm{~cm}$ height, $1 \mathrm{~cm}$ curvature radio on the tip) was manufactured and tested in a plasma torch facility for about 10 minutes at temperatures above $2000^{\circ} \mathrm{C}$. The nose-cone model was obtained from an hot-pressed billet via EDM.

Figure 5 shows the temperature history as recorded during the test. In figure 6 , the photograph of the nose after the test is exhibited.

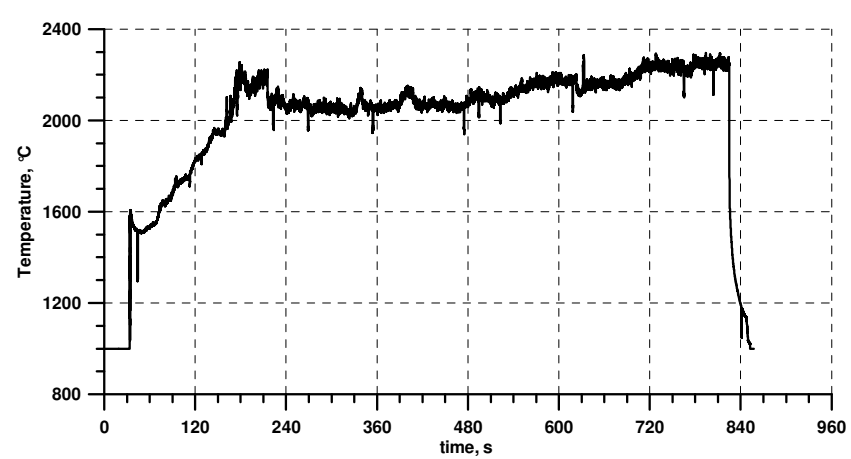

Fig. 5. Time-temperature history of the test

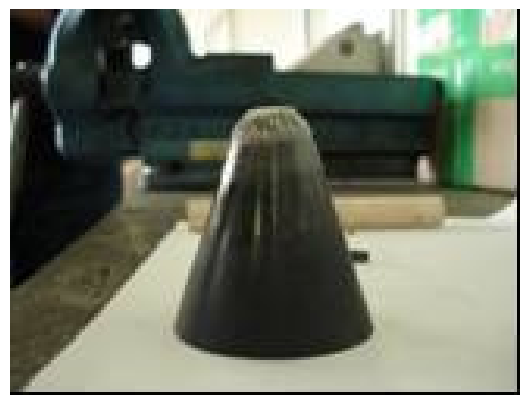

Fig. 6. The nose cap after the test

The post-test cross-sectioning of the model after exposure showed a promising potential to withstand severe re-entry conditions with temperature exceeding $2000^{\circ} \mathrm{C}$, thanks to the formation of a steady-state external multiphase oxide scale (Fig. 7).

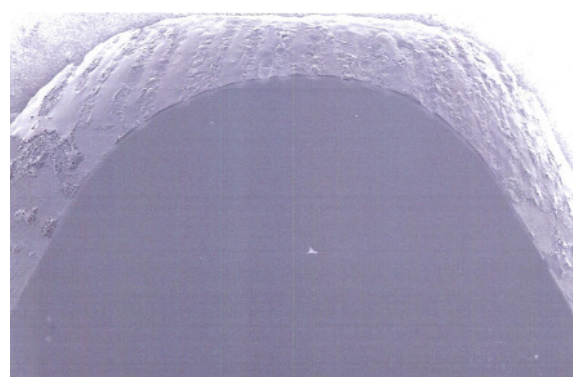

Fig. 7. SEM image of the cross section of the apex of the nose cone, after the plasma torch test

\section{Large Prototype Manufacturing}

A major critical issue with massive sintered UHTC or with monolithic ceramics in general, is represented by the mechanical jointing of small bulk components with large subtending long fibers ceramic matrix composites (CMC) or metal structures.

UHTC are indeed conceived for the realization of small parts like tips of nose caps or wing leading edges, to be mounted in the airframe structural areas that are mostly interested by extreme heating in a hypersonic re-entry maneuver. It is also important to note that, as of today, there are no reported examples of full scale TPS structures that make use of UHTC components.

Therefore, the coupling of UHTC components to CMC and/or metal structures has been studied extensively, and real scale technological demonstrators have been designed and manufactured, in order to be tested in CIRA's large scale Plasma Wind Tunnel Scirocco.

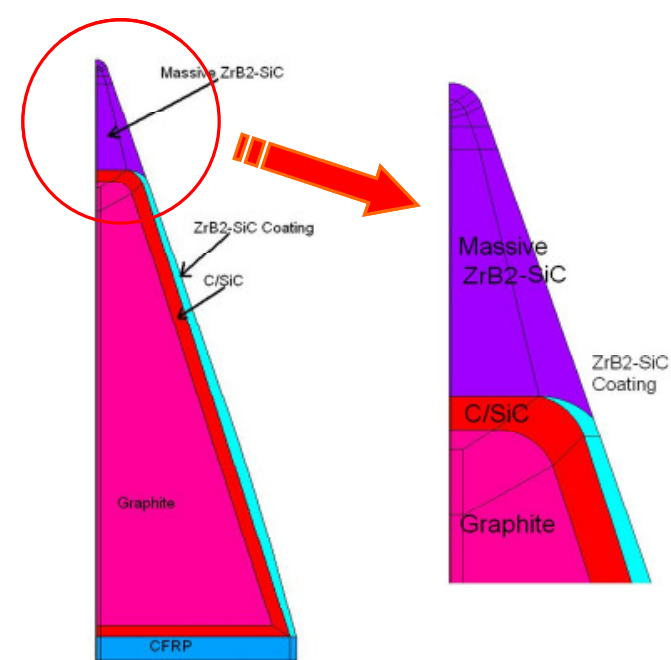

Fig. 8. Schematic of the large Nose Cone demonstrators material architecture

Figure 8 shows a schematic of the Nose cone demonstrator that was designed and assembled. The prototype is constituted of: 
- A graphite core;

- A C/SiC tronco-conical structural dome;

- A UHTC coating on the $\mathrm{C} / \mathrm{SiC}$, applied by plasma spray deposition and intended as a protection against oxidation;

- A monolithic UHTC conical tip.

The conical tip is assembled on the dome by mean of a titanium pin with a bayonet-like tip, shown in Fig. 9.
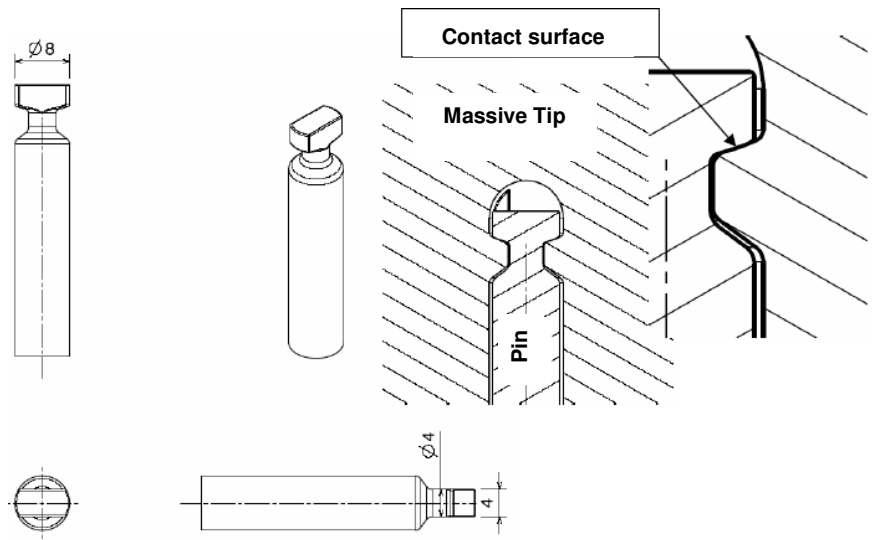

Fig. 9. Schematic of mechanical jointing between the UHTC monolithic tip and the subtending CMC structure

The UHTC conical tip, the $\mathrm{C} / \mathrm{SiC}$ dome prior to the UHTC coating deposition, and the final assembled Nose Cap are depicted in Fig. 10.

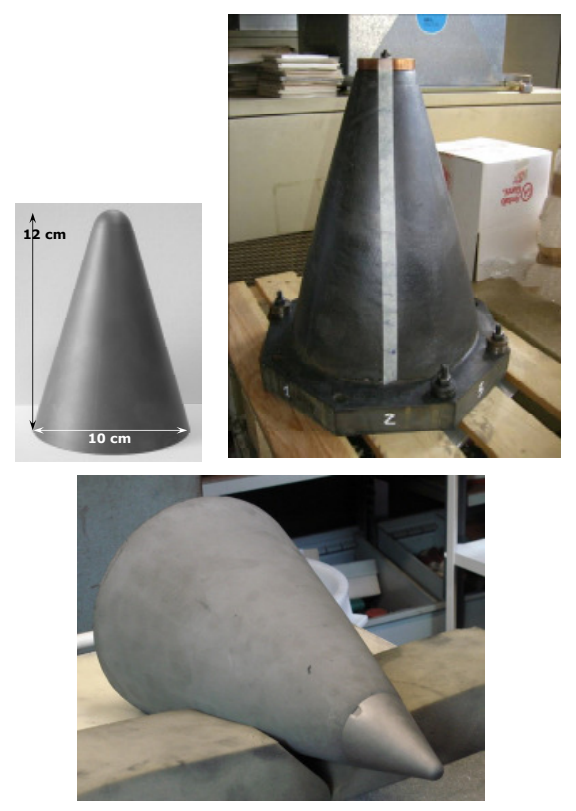

Fig. 10. UHTC conical tip (on the higher left), C/SiC dome (on the higher right) and the final assembled nose (lower centre)

\section{Future Outlooks}

Two main issues have emerged in the study of UHTC materials as candidate systems for hot structure manufacturing:

- Manufacturing costs and complexity: the EDM machining, while flexible and effective for shaping complex components out of massive sintered billets, is a an expensive and lengthy process

- Poor toughness of the UHTC materials, and associated low damage tolerance: being monolithic ceramics, UHTC materials suffer from a inherently brittleness that is extremely sensitive to defects and/or surface micro-damage; this leads to a poor damage tolerance

Given the necessity to lower manufacturing time and costs, and to the severe need for improvements in the field of overall reliability and damage tolerance, new solutions have been evaluated for the technology of UHTC materials and are currently under feasibility study. The first of them foresee the realization of long fibers reinforced UHTC matrix composites: such innovative CMC materials could potentially provide the increased temperature and oxidation resistance associated with the UHTC matrix with the damage tolerance and reliability of a long fiber reinforced CMC. Such UHTC-CMC could be realized by mean of a forced filtration process in hich UHTC powder in suspension inside a carrier solution are forcedly (with the application of external pressure) filtrated through the carbon fiber reinforcement, until a good level of matrix fill is achieved; a heat treatment in inert atmosphere performed as a second step could lead to the desired level of final density/compaction of the matrix. The second feasibility study foresee the investigation of innovative processes like slip casting, for the realization of near to final shape pieces, in order to minimize further machining, and, consequently, complexity and costs.

\section{Conclusions}

Two promising UHTC materials for the manufacturing of hot structures for hypersonic re-entry vehicles have been set up and fully characterized. The two materials exhibit remarkable mechanical properties if compared to similar ceramics reported in literature, have a good performance in high temperature in oxidative environment, and are characterized by high emissivity and low catalycity.

A small nose cone demonstrator manufactured and tested at ultra high (above $2000^{\circ} \mathrm{C}$ ) temperature in air for long time (around 10 minutes) have showed the good potential of these materials for the intended space application.

The technological issue of mechanical jointing of UHTC parts to conventional CMC or metal structure of a space vehicle airframe has been addressed and is currently under study. A real scale nose cone has been built and is scheduled to be tested in the Scirocco Plasma Wind Tunnel. 


\section{References}

1) Opeka, M. M., Talmy, I. G. and Zaykoski, J. A.: Oxidation-Based Materials Selection for $2000^{\circ} \mathrm{C}+$ Hypersonic Aerosurfaces: Theoretical Considerations and Historical Experience, J. Mater. Sci., 39 (2004), pp. 5887-5904.

2) Monteverde, F., Bellosi, A. and Guicciardi, S.: Processing and Properties of Zirconium Diboride-Based Composites, J. Eur. Ceram. Sci., 22 (2002), pp. 278-288.

3) Mroz, C.: Zirconium diboride, Am. Ceram. Soc. Bull., 73 (1994), pp. 141-142.

4) Fahrenholtz, W. G., Hilmas, G. E., Talmy, I. G. and Zaykoski, J. A.: Refractory diborides of zirconium and hafnium, $J$. Amer. Ceram. Soc., 90 (2007), pp. 1347-1364.

5) Upadhya, K., Yang, J.-M. and Hoffman, W. P.: Materials for ultra-high temperature structural applications, Am. Ceram. Soc. Bull., 58 (1997) pp. 51-56.

6) Gasch, M., Ellerby, D., Irby, E., Beckman, S., Gusman, M. and Johnson, S.: Processing, properties and arc-jet oxidation of hafnium boride/silicon carbide ultra high temperature ceramics, J. Mat. Sci., 39 (2004), pp. 5925-5937.

7) Levine, S. R., Opila, E. J., Halbig, M. C., Kiser, J. D., Singh, M. and Salem, J. A.: Evaluation of ultra-high temperature ceramics for aeropropulsion use, J. Eur. Ceram. Soc., 22 (2002), pp. 2757-2767.

8) Opeka, M. M., Talmy, I. G., Wuchina, E. J., Zaykoski, J. A. and Causey, S. J.: Mechanical, Thermal, and Oxidation Properties of Refractory Hafnium and Zirconium Compounds, J. Eur. Ceram. Soc., 19 (1999), pp. 2405-2414.

9) Opila, E., Levine, S. and Lorincz, J.: Oxidation of $\mathrm{ZrB}_{2}$ - and $\mathrm{HfB}_{2}$-based ultra-high temperature ceramics: Effect of Ta additions, J. Mater. Sci., 39 (2004), pp. 5969-5977.

10) Silvestroni, L. and Sciti, Diletta: Effects of $\mathrm{MoSi}_{2}$ additions on the properties of $\mathrm{Hf}-$ and $\mathrm{Zr}-\mathrm{B}_{2}$ composites produced by pressureless sintering, Scripta Mater., 57 (2007), pp. 165-168.

11) Zhang, X., Hu, P., Han, J. and Meng S.: The addition of lanthanum hexaboride to zirconium diboride for improved oxidation resistence, Scripta Mater., 57 (2007), pp.1036-1039.

12) Monteverde, F. and Bellosi, A.: Advances in microstructure and mechanical properties of zirconium diboride-based ceramics, Mater. Sci. Eng., A346 (2003), pp. 310-319.

13) Tripp, W. C. and Graham, H. C.: Thermogravimetric Study of the Oxidation of $\mathrm{ZrB}_{2}$ in the Temperature Range of $800^{\circ} \mathrm{C}$ to $1500^{\circ} \mathrm{C}$, J. Electrochem. Soc., 118 (1971), pp. 1195-1199.

14) Tripp, W. C., Davis, H. H. and Graham, H. C.: Effect of a SiC Addition on the Oxidation of $\mathrm{ZrB}_{2}$, Am. Ceram. Soc. Bull., 52 (1973), pp. 612-616.

15) Clougherty, E. V., Kalish, D. and Peters, E. T.: Research and Development of Refractory Oxidation Resistant Diborides, U.S. Air Force AFML-TR-68-190 (1968).

16) Kuriakose, A. K. and Margrave, J. L.: The Oxidation Kinetics of Zirconium Diboride and Zirconium Carbide at high Temperature, J. Electrochem. Soc., 111 (1964), pp. 827-831.

17) Chamberlain, A., Fahrenholtz, W., Hilmas, G. and Elleby D.: Oxidation of $\mathrm{ZrB}_{2}-\mathrm{SiC}$ Ceramics Under Atmospheric and Reentry Conditions, Refract. Appl., 1 (2005), pp. 1-8.

18) Ban'kovskaya, I. B. and Zhabrev, V. A.: Kinetic Analysis of the Heat Resistance of $\mathrm{ZrB}_{2}-\mathrm{SiC}$ Composites, Glass Phys. Chem., 31 (2005), pp. 482-488.
19) Rezaie, A., Fahrenholtz, W. G. and Hilmas G. E.: Evolution of structure during the oxidation of zirconium diboride-silicon carbide in air up to $1500^{\circ} \mathrm{C}, \mathrm{J}$. Eur. Ceram. Soc., 27 (2007), pp. 2495-2501.

20) Rezaie, A., Fahrenholtz, W. G. and Hilmas G. E.: Oxidation of Zirconium Diboride-Silicon Carbide at $1500^{\circ} \mathrm{C}$ at Low Partial Pressure of Oxygen, J. Am. Ceram. Soc., 89 (2006), pp. 3240-3245.

21) Monteverde, F. and Bellosi, A.: The resistance to oxidation of an $\mathrm{HfB}_{2}-\mathrm{SiC}$ composite, J. Eur. Ceram. Soc., 25 (2005), pp. 1025-1031.

22) Karlsdottir, S. N., Halloran, J. W. and Henderson, C. E.: Convection Patterns in Liquid Oxide Films on $\mathrm{ZrB}_{2}-\mathrm{SiC}$ Composites Oxidized at a High Temperature, J. Am. Ceram. Soc., 90 (2007), pp. 2863-2867.

23) Karlsdottir, S. N., Halloran, J. W. and Grundy, A. N.: Zirconia Transport by Liquid Convection during Oxidation of Zirconium Diboride-Silicon Carbide, J. Am. Ceram. Soc., 91 (2008), pp. 272-277.

24) Kolodziej, P., Salute, J. and Keese, D. L.: First Flight Demonstration oa a Sharp Ultra High Temperature Ceramic Nosetip, NASA TM-112215 (1997).

25) Marschall, J., Erlich, D. C., Manning, H., Duppler, W., Ellerby, D. and Gash, M.: Microhardness and High-Velocity Impact Resistence of $\mathrm{HfB}_{2} / \mathrm{SiC}$ and $\mathrm{ZrB}_{2} / \mathrm{SiC}$ Composites, $J$. Mater. Sci., 39 (2004), pp. 5959-5968.

26) Zimmermann, J. W., Hilmas, G. E., Fahrenholtz, W. G., Monteverde, F. and Bellosi, A.: Fabrication and properties of reactively hot pressed $\mathrm{ZrB}_{2}$-SiC ceramics, J. Eur. Ceram. Soc., 27 (2007), pp. 2729-2736.

27) Fahrenholtz, W. G., Hilmas, G. E., Chamberlain A. L. and Zimmermann, J. W.: Processing and Characterization of $\mathrm{ZrB}_{2}$-Based Ultra-High Temperature Monolithic and Fibrous Monolithic Ceramics, J. Mater. Sci, 39 (2004), pp. 5887-5904.

28) Bellosi, A., Monteverde, F., Dalle Fabbriche, D. and Melandri, C.: Microstructure and Properties of $\mathrm{ZrB}_{2}$-Based Ceramics, J. Mater. Process. Manu., 9 (2000), pp. 156-170.

29) Monteverde, F. and Bellosi, A.: Oxidation of $\mathrm{ZrB}_{2}$-Based Ceramics in Dry Air, J. Electrochem. Soc., 150 (2003), pp. B552-B559.

30) Monteverde, F. and Bellosi, A.: Microstructure and Properties of an $\mathrm{HfB}_{2}-\mathrm{SiC}$ Composite for Ultra-High Temperature Applications, Adv. Eng. Mat., 6 (2004), pp. 331-336.

31) Russo, G. and Marino G.: The USV Program \& UHTC Development, Proceedings of the $4^{\text {th }}$ European Workshop on Thermal Protection Systems for Space Vehicles, edited by A. Wilson, European Space agency, Paris, 2003, pp. 157-163.

32) Monteverde, F., Bellosi, A. and Scatteia, L.: Processing and properties of ultra-high temperature ceramics for space applications, Mater. Sci. Eng. A, 485 (2008), pp. 415-421.

33) Scatteia, L., Borrelli, R., Cosentino, G., Bêche, E., Sans, J.-L. and Balat-Pichelin, M.: J. Spacecraft Rockets, 43 (2006), pp. 1004-1012.

34) Scatteia, L., Alfano, D., Monteverde, F., Sans, J.-L. and Balat-Pichelin, M.: Effect of the Machining Method on the Catalycity and Emissivity of $\mathrm{ZrB}_{2}-\mathrm{HfB}_{2}$-Based Ceramics, $J$. Am. Ceram. Soc., 91 [5] (2008), pp. 1461-1468. 